Original Research

\title{
Fear of Falling Among the Elderly in a Nursing Home: Strongest Risk Factors
}

\section{Anastasia Putu Martha Anggarani and Raditya Kurniawan Djoar}

STIKES Katolik St. Vincentius A Paulo, Surabaya, Indonesia

\begin{abstract}
Introduction: The aging process causes a decrease in physical abilities which can cause fall events. Fall events are influenced by fear of falling. Some risk factors of fear of falling were age, gender, balance while walking, use of a walker, depression and a history of previous falls. This study aim was to identify risk factors related to fear of falling among the elderly in nursing home.

Methods: A cross-sectional study was used in this study. Respondents were elderly aged $\geq 60$ years, can communicate well, able to read and write and not being sick which causes balance disorders and pain when walking. Respondents totaled 155 obtained by proportional random sampling. A questionnaire was used to retrieve data such as age, gender, use of a walker, depression, previous fall history and balance walking.

Results: The results showed a significant relationship between all of these risk factors with the fear of falling $(\mathrm{p}<0.05)$ and the power of significance for each variable was different. The age variable was power significance 0.228 , gender $C$ $=0.2$, previous fall history $C=0.374$, use of a walker $C=0.367$, balance walking $\mathrm{C}=0.355$ and depression $\mathrm{rs}=0.196$. There are three risk factors most closely associated with fear of falling in terms of balance walking $(B=1.424 \operatorname{Exp}(B)=$ $4,153)$, use of a walker $(B=1,365 \operatorname{Exp}(B)=3,914)$ and previous fall history $(B=$ $1.425 \operatorname{Exp}(B)=4.159)$. These factors had strength of $27 \%$.
\end{abstract}

Conclusion: Balance walking, use of a walker and previous fall history were the strongest risk factors.

\section{ARTICLE HISTORY}

Received: June 17, 2019

Accepted: April 30, 2020

\section{KEYWORDS}

elderly; fear of falling; nursing home

\section{CONTACT}

Raditya Kurniawan Djoar $\triangle$ radit stikvinct@yahoo.com $\ggg$ STIKES Katolik St. Vincentius A Paulo, Surabaya, Indonesia

Cite this as: $\quad$ Djoar, R.K., \& Anggraini, A. P. M. (2020). Fear of Falling Among the Elderly in a Nursing Home: Strongest Risk Factors. Jurnal Ners, 15(1). 59-65. doi:http://dx.doi.org/10.20473/jn.v15i1.13689

\section{INTRODUCTION}

The aging process causes a decrease in physical ability and further can cause the incidence of fall, especially for the elderly. The number of falling in the elderly is quite high, at least $28 \%-35 \%$ of 65 year-old people fall every year and the number increases to $32 \%-42 \%$ in the elderly over 70 years (World Health Organization, 2007). Fall events are influenced by several factors, one of which is the personal factor of fear of falling. As to psychological status of fear of falling, up to $70 \%$ of recent fallers and up to $40 \%$ of those not reporting recent falls acknowledge the fear of falling $(25,38,55)$. Up to $50 \%$ of people who are fearful of falling restrict or eliminate social and physical activities because of that fear (WHO, 2004).

Fall events are influenced by several factors, one of which is the personal factor of fear of falling. Fear of falling is an internal phenomenon or anxiety associated with falls that can affect a person's level of dependence which results in a decrease in function when doing activities. Fear of falling is a residual symptom of falling, but can also occur in people who have never fallen. This incident occurs above $60 \%$ in the elderly aged $60-79$ years (Howland, 1998). Fear of falling can affect quality of life for the elderly and increase the risk of falling through the reduction of physical activity, confidence, strength, and balance. Fear of falling can reduce balance control and reduced the confidence to prevent falls, further increasing the incidence of falls for the elderly (Public Health Agency of Canada, 2005).

Fear of falling is feeling anxious when walking or mobilizing normally or normally, it can cause falls (Greenberg, 2011). The current study showed around $26 \%-55 \%$ of elderly people living in the community were fearful of falling, and $40 \%-73 \%$ of the elderly who had fallen had fear of falling (Howland, 1998). In many ways, the fear of falling potentially causes restrictive movement, especially 
for the elderly. That condition can decrease the independence of the elderly in daily activities (Murphy, 2002), decreased quality of life of elderly and decreased social interaction (Austin et al., 2007).

The prevalence of fear of falling is in line with age (Scheffer et al., 2008). Aging will lead to physiological changes in the body's systems, such as the musculoskeletal, cardiovascular, respiratory, nervous, sensory and other organ functions (Narinder \& Verma, 2007). Because of physiological changes during the aging process, the elderly will have difficulty maintaining balance while performing activities. This situation can produce fear of falling during a functional activity.

Several studies of fear of falling have identified the prevalence of more women (Susan et al., 2002). In one study conducted on 1000 women over three years, more than one-third of the samples reported fear of falling and increased $45 \%$ after three years (Lach, 2005). The fear of falling is also influenced by the ability to maintain balance while walking (Jacobs \& Fox, 2008). People with impaired balance have lost confidence to rest with the feet, especially when walking (Fletcher \& Hirdes, 2004; Kumaret al., 2008)) so that it will increase the fear of falling.

Psychological conditions, especially depression, also become one of the risk factors in fear of falling. Depression has a strong relationship with the fear of falling and can cause the limitations of physical and social activity (Jung, 2008). When the ability to do activity is decreased, elderly people will feel not confident and increase further fear of falling. Depression can also make people less secure about their physical abilities, thus causing fear of falling (Legters, 2002).

Several studies have shown a positive relationship between fear of falling and a previous fall history. A person who often experiences a fall will increase the incidence of fear of falling (Jung, 2008). Elderly people who have fallen are also more difficult to maintain balance as they perform their functional activities for fear of falling (Kumaret al., 2008). Elderly people who feel fear of falling will protect themselves by using walking aids to reduce the fear (Victorian Quality Council, 2004). However, the elderly dependency on walking aids will also increase the fear of falling.

Several factors have a positive relationship with fear of falling; therefore, through this study, we want to identify the strongest risk factors that have been mentioned. So, it will be very helpful in determining the intervention, especially sports activities appropriate for the elderly who can support the maintenance of independence, function, health, and safety for them so it can be used as a preventive effort to reduce the incidence rate of fall in the elderly (Greenberg, 2011).

\section{MATERIALS AND METHODS}

This study was carried out at private and government nursing homes, St Yosef nursing home, Surya nursing home, Usia nursing home, Griya Wredha nursing home, Anugerah Surabaya nursing home, and Yayasan Cinta Kasih Ibu Teresa, between 1 March and 29 May 2016. The study protocol was approved by the ethical committee on health research, Faculty of Medicine, Airlangga University, Indonesia. Informed consent was obtained from all of the respondents.

This study was conducted at 155 elderly determined by a proportional random sampling technique. Independent variables in this study are age, gender, previous fall history, use of a walker, depression status, and balance ability, while the dependent variable is fear of falling. The data were obtained by using questionnaire. The questionnaire containing questions about age, gender, previous fall history and use of a walker. To fill in the age data, the respondents fills his / her age in the questionnaire in year, gender, for the data of previous fall history, respondents select "yes" or "no" items in the questionnaire, and for the data of the use of the walker, respondents select item "yes" or "no" in the questionnaire.

To obtain the fear of falling data, we used the Questionnaire Modified Fall Efficacy Scale Indonesia Version with content validity item in the range of 0.857 - 1 (valid value> 0.78 ), while the Sum-Content Validity Index obtained the result 0.93 (valid value> 0. 9) with Cronbach's alpha value 0.948), and to obtain depression data we used the Indonesian version of the geriatrics depression scale (GDS) questionnaire with Cronbach's alpha value of 0.88 (Himawan, Rinawaty, \& Wirawan, 2014), in addition, we used the Time Up and Go Test (TUGT) with interrater of 0.94 and intra rater of 0.95 to obtained balance walking data (Asnandra, 2009).

The data were recapitulated, entered into the SPSS program and analyzed. Spearman test was used to identify correlation for age, depression, and fear of falling and the other data used Contingency Coefficient to identify the correlation between gender, previous falls history, use of a walker, balance ability with fear of falling. To identify the risk factor, binomial logistic regression was used.

\section{RESULTS}

Characteristics of respondents in this research are average 76 years with a percentage equal to $70.3 \%$ and female. Of the 155 respondents it was found $58.1 \%$ had experienced a fall. As many as $65.2 \%$ are not depressed. Respondents in this study, as many as $65.8 \%$, had a risk of falling and $74.2 \%$ of them did not use a walker. A total of $49.7 \%$ of respondents have high concerns about falling (Table 1). 
Table 1. Demographics (n: 155)

\begin{tabular}{|c|c|c|}
\hline Variable & Sub Group & Mean $\pm S D / n(\%)$ \\
\hline Age & & $76.3 \pm 8.02$ \\
\hline \multirow[t]{2}{*}{ Gender } & Male & 46 (29.7\%) \\
\hline & Female & $109(70.3 \%)$ \\
\hline \multirow[t]{2}{*}{ Previous fall history } & Yes & $90(58.1 \%)$ \\
\hline & No & $65(41.9 \%)$ \\
\hline \multirow[t]{2}{*}{ Use of a walker } & Yes & $40(25.8 \%)$ \\
\hline & No & $115(74.2 \%)$ \\
\hline \multirow[t]{3}{*}{ Balance walking } & & $22.3 \pm 14.6$ \\
\hline & Risk of Falls & $102(65.8 \%)$ \\
\hline & No risk of Falls & $53(34.2 \%)$ \\
\hline \multirow{4}{*}{ Depression } & & $8.5 \pm 5.1$ \\
\hline & Normal & $101(65.2 \%)$ \\
\hline & Mild Depression & $50(32.3 \%)$ \\
\hline & Moderate Depression & $4(2.6 \%)$ \\
\hline
\end{tabular}

Table 2. Correlation Analysis

\begin{tabular}{lcc}
\hline & Variable & Fear of Falling \\
& rs & C \\
\hline Age & $0.228^{* *}$ & $0.200^{*}$ \\
Gender & & $0.374^{* * *}$ \\
Previous fall history & & $0.367^{* * *}$ \\
Use of a walker & & $0.355^{* * *}$ \\
Balance walking & $0.196^{*}$ & \\
Depression & & \\
\hline
\end{tabular}

${ }^{*} \mathrm{p}<.05$;** $^{*}<.01 ;^{* * *} \mathrm{p}<.001$

Table 3. Binomial Logistic Regression Test Analysis

\begin{tabular}{lcccccc}
\hline & B & Sig. & Exp(B) & \multicolumn{2}{c}{ 95\% C.I.for EXP(B) } & Cox \& Snell R Square \\
& & & & Lower & Upper & \\
\hline Previous fall history & 1.424 & 0.000 & 4.153 & 1.913 & 9.016 & \\
Use of a walker & 1.365 & 0.006 & 3.914 & 1.474 & 10.395 & \\
Balance walking & 1.425 & 0.001 & 4.159 & 1.820 & 9.501 & 0.276 \\
Constants & -2.116 & 0.000 & & & & \\
& & & & & & \\
\hline
\end{tabular}

Table 4. Chance of Fear of Falling

\begin{tabular}{cccc}
\hline Risk of Falls & Use of a walker & Previous fall history & \% Chance of Fear of Falling \\
\hline No & No & No & $10.76 \%$ \\
No & Yes & No & $32.06 \%$ \\
No & No & Yes & $33.36 \%$ \\
Yes & No & No & $33.39 \%$ \\
No & Yes & Yes & $66.23 \%$ \\
Yes & No & Yes & $67.57 \%$ \\
Yes & Yes & No & $66.23 \%$ \\
Yes & Yes & Yes & $89.07 \%$ \\
\hline
\end{tabular}

Spearman test was used to identify correlation for age, depression, and fear of falling and the other data used Contingency Coefficient to identify the correlation between gender, previous fall history, use of a walker, and balance ability with fear of falling. The correlation analysis in this study showed that there was a moderate correlation between the previous fall history and the fear of falling $(\mathrm{C}=$ $0.374 ; p=0.000)$, the use of walking aids with fear of falling ( $\mathrm{C}=0.367, \mathrm{p}=0.000)$ and the balance walking with fear of falling $(C=0.355 ; p=0.000)$ (Table 2)

Multivariate analysis in this study used a binomial logistic regression test. We used this test because the correlation test of risk factors fear of falling to fear of falling is not strongly related and we assume the possibility of any relationship between each risk factor. The previous fall history, the use of walkers and the current balance is the strongest risk factor for fear of falling (Cox \& Snell R Square $=0.276$ ). Respondents experiencing one of these three risk factors risk an average of four times more with high fears of falling $(\operatorname{Exp}(B)=3,914$ 4,159 ) (Table 3). Respondents who do not have a risk of falling, do not use walking aids and do not have a previous fall history still have a chance of fear of falling by $10.76 \%$. Respondents who are at risk of falling, using walking aids and having a previous fall history have a high probability of falling $89.07 \%$. To identify the chance of power independent variable to the dependent variable, the researcher using the formula $\mathrm{P}: 1 / 1+\mathrm{e}^{-\mathrm{y}} . \quad(\mathrm{Y}=-2,116+1,425$ balance ability +1 , and use of a walker +1 , previous fall 
history. The formula used by researchers has a precision of $74.8 \%$.

Equation:

$$
\mathbf{H}^{s}=-\sum_{i=1}^{g}\left(P_{i}\right)\left(\log _{2} P_{i}\right)
$$

Remarks:

\section{DISCUSSION}

This study showed $58.1 \%$ of respondents had a history of previous falls. The result of the correlation analysis $\mathrm{p}=0.000 \mathrm{r}=0.374$ indicating that the previous fall history has a moderate strength relationship with fear of falling. The logistic regression analysis test showed the result of significance $p=0.000$ with the positive direction indicated by the value of $B=1.423$. This is by the theory that a person who often experiences a fall will increase the incidence of fear of falling (Jung, 2008). When viewed from the chances of respondents who have a history of falling and experiencing high fears they will fall, this obtained data of $33.3 \%$ and $76.62 \%$ of respondents who have a history of falls have high worries they will fall. Other studies with elderly respondents also reported that there was a significant correlation between previous fall history and fear of falling (Lopes, Costa, Santos, Castro, \& Bastone, 2009). The fear of falling can be described depending on the experience of the previous fall and the increased fear of falling with the fall type (Arken et al., 1994). Fall events that cause serious injury further increase the fear of falling (Salkeld et al., 2000). Elderly people who have experienced a previous fall not only impact on their physical condition, but have an impact on the psychological conditions in which they will feel traumatized by such unpleasant events and afraid to fall again when they do the activity. This condition will have an impact on the decline in social activity and confidence.

This study has the result explain that although respondents who never fall but they have risk of falls and using a walking aid, they have a chance $66.23 \%$ fear of falling (Table 4). This is in line with previous research by Lopes et al. (2009) where the incidence of fear of falls occurred by $12 \%-65 \%$ in the elderly who live in the community, aged over 60 years and have no previous fall history. The results obtained in this study indicate that most respondents who have a fear of falling do not have a previous fall history (Lopes et al., 2009). This condition can occur because the fear of falling is a multifactor event, so that not only the previous fall history can cause fear of falling. Elderly people who do not have a previous fall history may experience fear of falling. This fear can be a safeguard to be more careful to avoid the risk of falling, but also can be a risk when it results in limitations and lack of confidence when doing activities.

The previous fall history is one of the biological factors of fear of falling. To determine the appropriate intervention in this risk factor, it is necessary to examine the type of activity, the time of the fall, the frequency of fall, the injury suffered and the symptoms at the time of fall. If the elderly have a history of falling due to unsafe environmental causes for the elderly to walk, then appropriate intervention is to change the environment to be safe for the elderly, for example: to give a handle in every aisle used by the elderly to walk so that the elderly remain confident not to fall. Interventions that can be done in the elderly with a history of previous fall include trying to stay active, always positive thinking, take care of yourself and do relaxation exercises (Shaw, 2010).

For these three things, balance is one of the key moves (Allison, 2001). Balance, strength, and flexibility are needed to maintain good posture. These three elements are the basis for realizing a good road pattern for each individual. Important mechanisms for each individual to have a good balance involve the peripheral nervous system, proprioceptive (sense of joint position), vestibular and cerebral and visual (vision) (Skelton, 2017), otherwise known as postural control, which is the ability to maintain balance and orientation in the gravitational environment. According to Lopes et al. (2009), postural control consists of three components, peripheral sensory system, central system, and effector system, and the elderly will experience a decrease in function, as well as peripheral nerves. Central processing runs slowly as well as in the interpretation and sensory information of the system and recruitment of motor planning, and careful environmental responses. Peripheral nerves, skeletal muscle mass and muscle strength decrease in function causing postural control to be slower and weaker. This decrease in function will disturb the balance, which will ultimately lead to a greater risk of falling (Jette, 2012).

In this study data obtained $65.8 \%$ of respondents have the risk of falling. The result of the correlation analysis is $\mathrm{p}=0.000 \mathrm{r}=0.355$, which shows that the current balance has a medium relationship with the strength of the relationship. The logistic regression analysis test showed the result of significance $p=0.001$ with the positive direction indicated by the value of $\mathrm{B}=1.425$. Research conducted by Boyd and Stevens (2009) shows a relationship between decreasing balance and fear of falling. Posture control, voluntary movement stability, and reaction maintain balance when being subjected to outside interference is the basis for maintaining balance. Postural control involves the integration of sensory, nervous, and musculoskeletal systems, so the center of mass remains at bases of support and center of gravity moves along with a change in the base of support so that balance can be formed (Miyamoto, Lombardi, Berg, Ramos, \& Natour, 2004).

Another study reported that $78.91 \%$ of respondents experienced partial independence during transfer, $50.34 \%$ indicated a fear of falling through the tandem gait test (correlation $r=0.457$ ) 
and $31.39 \%$ decreased equilibrium (correlation $r=$ 0.44248) (Lopes et al., 2009). This is in line with this study that there is a relationship between the current balance and the fear of falling. Fear of fall is the result of the recruitment of agonist and antagonist muscle work while maintaining poor posture, abnormal road patterns, poor balance strategy, depending on assistive devices that ensure stability and increased risk of falls in the elderly. When a person is feeling unbalanced when doing activities, especially walking, this will directly make the individual afraid to perform activities because of changes in the balance that can consciously cause a fall when forced to move. Likewise, in the elderly, physical changes are closely related to the balance in walking. The chance of respondents experiencing high concerns they will fall in respondents who have a risk of a fall is $33.39 \%$. Medical conditions associated with a disturbance of equilibrium greatly affect the increased fear of falling because people with impaired balance have lost the confidence to rest with the foot, especially when walking (Kumar, Venu Vendhan, Awasthi, Scholar, \& Tiwari, 2008). Therefore, it is necessary to identify the main factors causing the imbalance so that appropriate interventions can be given to improve the balance of the elderly.

To determine the appropriate intervention of this risk factor, an examination consisting of a path pattern examination, balance and joint function on the lower extremities is required. One of the interventions that can improve balance is tai chi gymnastics. This is shown in a study conducted by Scheffer, Schuurmans, van Dijk, van der Hooft, and de Rooij (2007) which found that there is an increase in balance during activity. Tai chi is a sport that contains slow, rhythmic movements, many involving trunk movements, weight transfer, coordination, and pedestrian refinement. This gymnastic activity is performed for 60-90 minutes for two sessions per week.

This study shows $25.8 \%$ of respondents using road aids. The result of the correlation analysis $\mathrm{p}=$ $0.000 \mathrm{r}=0.367$ indicates that the use of the walker has a relation with the medium strength of the relationship. The logistic regression analysis test showed the result of significance $p=0.006$ with the positive direction indicated by value $B=1.365$. Opportunities of respondents using of road aids experienced high concerns about falling (32.06\%). The elderly use walking aids for various reasons, namely as a therapeutic tool to train post-injury walking skills, the elderly with neurological disorders, and to further reduce the fear of falling (World Health Organization, 2007). The use of a walker has a protective effect on falls in the elderly as it helps elderly people with mobility limitations when engaging in activities with disturbances from the environment (Rayel, Land, \& Gutheil, 1999). Elderly using a walker already have concerns about falling if they do activities. This is in line with the theory so they compensate by using a walker to reduce the fear of falling.

This is in line with research conducted by Multani andc Verma (2007) in 43 elderly people ( $\geq$ 60 years) where 22 people (51\%) used a walker at least one year. The reason for the respondents using the walker was because they were afraid of falling as much as $54.5 \%$, while the other reason was finding security (27.3\%), and habituation following surgery/injury (18.2\%).

This study also obtained the data of respondents who do not use a walker, but have a high concern they will fall, as many as 45 people (58.44\%). Elderly do not use walkers because they feel embarrassed / considered disabled, elderly and feel by using a walker it will restrict its activity because the use of a walker can affect the pattern of the road by inhibiting swing pattern, affect posture, reduce road speed, step length and swing time, and stance time (World Health Organization, 2007). It will cause more fear of falling. Besides, the elderly judge that the environment around them does not support them to use the walker. Another thing that causes those who do not use the walker, but still experience high worries they will fall, with 32 respondents have a history of falling before, 32 people have a risk of falling, and 22 people have a history of previous fall and have the risk of falling.

Some elderly people have difficulty when using a walker. Therefore, the should be trained in advance in the use of a walker, especially in the elderly, on how to use the right aids so that the elderly are confident in using the tool so that the fear of falling can be reduced (Bradley \& Hernandez, 2011).

This study reported that the probability of experiencing heightened fear of fall over those who do not have a risk of falling / balancing when walking well, not having a previous fall history and not using a walker is $10.76 \%$. This concern can be a protective order to be more careful to avoid the risk of falling during the move.

Opportunities experiencing heightened concerns they will fall over those who have had a previous fall history and use the walker is $66.23 \%$. One study reported that, from 199 respondents, 56 respondents $(28.4 \%)$ often experienced a fall in the last 12 years, eight respondents (4.1\%) had experienced a fall of one time to cause injury and 32 respondents (16.2\%) never experienced a previous fall without causing injury. Respondents who had experienced the fall using a walker and experienced fear of falling (Roman de Mettelinge \& Cambier, 2015). The elderly who have experienced a fall have low confidence when doing activities for fear of falling owned. To increase confidence to feel a sense of security while doing activities and avoid the risk of falling back, some elderly use a walker because it helps to maintain balance while on the move.

People who have a risk of falling / balancing on a bad run and using a walker have a chance of high worries will fall by $67.57 \%$. The use of a walker indicates the occurrence of a balance disorder or 
may cause one to lose balance due to an increase in attention requirement (Public Health Agency of Canada, 2005), and it can cause fear of falling.

People who have a risk of falling/balancing on a bad run and having a previous history of falling have a chance of high worries they will fall by $66.23 \%$. Ability to maintain balance while on the move/walking is done by several systems in the body. When considering elderly experiencing a decline in anatomical and physiological functions, the ability will be reduced, resulting in the elderly often experiencing a fall during the move. Therefore, the elderly who have often experienced a fall because of balance going bad will experience the fear of falling to a higher extent.

According to this study, if people have a risk of falling / balancing when walking is bad, having a history of previous falls and using a walker, they will have a chance of experiencing high worries they will fall by $89.07 \%$ (Table 4). This is because of the three things are the most dominant factors in the fear of falling. The elderly having a poor balance will feel insecure when using foot as a pedestal. This causes an increased risk of falling in the elderly. The elderly who had fallen had a sense of trauma and confidence reduction during the move, so used a walker. The use of a walker will also cause the elderly to have unusual road patterns, reduce swing while walking, affect posture, reduce road speed, length of step and stance time, and then will increase worries of fall.

\section{CONCLUSION}

The strong predictor of the fear of falling in the elderly was the use of walkers, balance and previous fall history. Therefore, based on this study people who have responsibility in the nursing home have to provide regularly activities such as gymnastics which can improve the balance of the elderly, also provide consultation for the elderly to be able to increase self-confidence, especially for those who have a history of previous falls, and modify the environment to add handrails in the area used by the elderly to reduce fears of falling.

\section{REFERENCES}

Allison L., F. K. (2001). Balance And Vestibular Disorder, Neurogical Rehabilitation (4th ed.). Mosby.

Arken, C. L., Lach, H. W., Birge, S. J., \& Miller, J. P. (1994). The Prevalence and Correlates of Fear of Falling in Elderly Persons Living in the Community. American Journal of Public Health, 84, 565-570.

Asnandra, N. (2009). Uji Reliabilitas Time Up and Go Test pada Lansia Perempuan. Politeknik Kesehatan Surakarta.

Austin, N., Devine, A., Dick, I., Prince, R., \& Bruce, D. (2007). Fear of falling in older women: A longitudinal study of incidence, persistence, and predictors. Journal of the American Geriatrics Society, 55(10),

1598-1603. https://doi.org/10.1111/j.1532-

5415.2007.01317.x

Boyd, R., \& Stevens, J.A. (2009). Falls and fear of falling : burden, beliefs and behaviours. Oxford Journal, 38, 423-428. https://doi.org/10.1093/ageing/afp053

Bradley, S. M., \& Hernandez, C. R. (2011). Geriatric assistive devices. American Family Physician, 84(4), 405-411.

C.Scheffer, A., J.Schuurmans, M., Dijk, N. van, Hooft, T. Van der, \& de Rooij, S. E. . (2008). Fear of falling: measurement strategy, prevalence, risk factors and consequences among older persons. Age and Ageing, 37, 19-24. https://doi.org/10.1093/ageing/afm169

Fletcher, P. C., \& Hirdes, J. P. (2004). Restriction in activity associated with fear of falling among community-based seniors using home care services. Age and Ageing, 33(3), 273-279. https://doi.org/10.1093/ageing/afh077

Friedman, S.M. (2002). Falls and Fear of Falling: Which Comes First? A Longitudinal Prediction Model Suggests Strategies for Primary and Secondary Prevention. Journal of the American Geriatrics Society, 50:1329-1335.

Greenberg, S. A. (2011). Assessment of Fear of Falling in Older Adults: The Falls Efficacy ScaleInternational ( FES-I ). Hartford Institute for Geriatric Nursing, 45(29). https://doi.org/10.1159/000320054.Kempen

Himawan, K. ., Rinawaty, W., \& Wirawan, H. . (2014). Effect of reminiscence group therapy on depressive symptoms of the nursing home elderly residents in Tangerang, Indonesia: A pilot study. The Guidance Journal, 45(1), 1-22.

Howland, J. (1998). Covariates of Fear of Falling and associated activity curtailment. Gerontologist, $38(5)$.

Jacobs, M., \& Fox, T. (2008). Using the " Timed Up and Go / TUG" Test to Predict Risk of Falls. Assisted Living Consult, (April).

Jette, A. M. (2012). Fear-of-Falling in Older Persons. Fear of Falling in Older Persons.

Jung, D. (2008). Fear of Falling in Older Adults: Comprehensive Review. Asian Nursing Research, 2(4), 214-222. https://doi.org/10.1016/S19761317(09)60003-7

Kumar, S., Awasthi, S., Sharma, V.P., Vendhan, G.H,, \& Tiwari, M. (2008). Relationship Between Fear of Falling, Balance Impairment and Functional Mobility in Community Dwelling Elderly. Indian Journal of Physical Medicine and Rehabilitation, 19(482), 48-52.

Lach, H. W. (2005). Incidence and risk factors for developing fear of falling in older adults. Public Health Nursing, 22(1), 45-52.

Legters, K. (2002). Fear of Falling. Physical Therapy Uournal of the American Physical Therapy Association, 82 no.3, 264-272. Retrieved from https://www.msconnection.org/Blog/Novembe r-2013/Fear-of-Falling

Lopes, K.T., Costa, D.F., Santos, L.F., Castro, D.P., \& 
Bastone, A.C. (2009). Prevalence of fear of falling among a population of older adults and its correlation with mobility, dynamic balance, risk and history of falls. Revista Brasileira de Fisioterapia, 13(June), 223-229.

Miyamoto, S. T., Lombardi, I., Berg, K. O., Ramos, L. R., \& Natour, J. (2004). Brazilian version of the Berg balance scale. Brazilian Journal of Medical and Biological Research, 37(9), 1411-1421. https://doi.org/10.1590/S0100879X2004000900017

Murphy, S. L. (2002). Characteristics Associated with Fear of Falling and Activity Restriction in Community-Living Older Persons. J Am Geriatr Soc, 50 (3).

Multani, N.K., \& Verma, S. K. (2007). Principles of Geriatric Physiotherapy.

Public Health Agency of Canada. (2005). Report on Seniors' falls in Canada. Canada: Minister of Public Works and Government Services Canada.

Rayel, M. G., Land, W. B., \& Gutheil, T. G. (1999). Dementia as a risk factor for homicide. JForensic-Sci, pp. 565-567.

Roman de Mettelinge, T., \& Cambier, D. (2015). Understanding the relationship between walking aids and falls in older adults: a prospective cohort study. Journal of Geriatric Physical Therapy (2001), 38(3), 127-132. https://doi.org/10.1519/JPT.00000000000000 31
Salkeld, G., Cameron, Cumming, R. G., Easter, S., Seymour, J., Kurrle, S. E., \& Quine, S. (2000). Quality of life related to fear of falling and hip fracture in older women: a time trade off study. British Medical Journal, 320, 341-346.

Scheffer, A. C., Schuurmans, M. J., van Dijk, N., van der Hooft, T., \& de Rooij, S. E. (2007). Fear of falling: measurement strategy, prevalence, risk factors and consequences among older persons. Age and Ageing, 37(1), 19-24. https://doi.org/10.1093/ageing/afm169

Shaw, G. B. (2010). Fear of Falling and Anxiety. Retrieved from http://www.catounbound.org/2010/04/07/richard-thaler/fearof-falling/

Skelton, T. (2017). Risk Factors for Falls. National Center for Injury Prevention and Control, 12.

Victorian Quality Council. (2004). Minimising the Risk of Falls \& Fall-related Injuries. Melbourne Victoria: Metropolitan Health and Aged Care Services Division.

WHO. (2004). What are the main risk factors for falls amongst older people and what are the most effective interventions to prevent these falls? (March).

World Health Organization. (2007). WHO Global Report on Falls Prevention in Older Age WHO Global Report on Falls Prevention in Older Age. Perancis: WHO. 